\title{
AUTOMOBILE DESIGN HISTORY - WHAT CAN WE LEARN FROM THE BEHAVIOR AT THE EDGES?
}

Chris Dowlen

Engineering and Design, London South Bank University, UK

London South Bank University, Borough Road, London SE1 0AA, UK.

chris.dowlen@1sbu.ac.uk 


\section{Automobile design history - what can we learn from the behavior at the edges?}

The paper is developed from a larger evaluation of the history of automobile design. This evaluation used categorical principal component analysis to analyze the direction of the product history, investigating how automobiles developed from 1878 to the present (2013), particularly focusing on whether automobile designers appear to be working within what are termed product paradigms. Rather than looking at how design thinking and paradigms became established in automobile design, this paper takes a sideways look at the variations and quirky automobiles that have been built by investigating the outliers of the analysis and categorizing them into three categories: those that are always outside of general trends, those that are throwbacks to earlier thinking and those that are innovative and ahead of later thinking. The paper ends with a brief look at how and why novelty might become innovation and hence alter the course of the greater product history rather than remaining outliers, interesting as they are. This is where the novelty demonstrates significant advantages for the customer and manufacturer. The conclusion is that the process of investigating statistical outliers is useful and may lead to insights when investigating changes, developments and innovations and their causes.

Keywords: automotive design; product history, principal components analysis, innovation, outliers, out-of-the-box thinking

\section{Introduction}

\subsection{The background to the gestation of the paper}

This paper started life as a conference paper with the title of Creativity in Car History: the behaviour at the edges (Dowlen, 2012). It describes a particular method to investigate historical designs that were out of the ordinary and removed from timeaccepted norms of the industry. The suggestion is that significant and satisfactory innovatory changes always take place at the edges of developments: that an investigation of what is taking place in the product mainstream will not indicate the future state of the art. Whilst this is true, investigating the edges of the statistical analysis identifies that other things are also taking place.

Historical investigation is not considered significantly within the design process literature. Jones (1981) considers the historical design processes of development and gradual change, and Kumar (2013) develops two historical mapping methods - 
Innovation Landscape (Section 1.8) and Eras Map (Section 2.4), identifying that these methods both create overview. The first identifies opportunities and the second organizes information in a coherent fashion. Both methods use qualitative analysis. Innovation Landscape generates uses of particular business terms in history and Eras Map identifies attributes and their characters and how these change over time.

The use of statistical processes to analyze historical examples of automobiles can create its own definition for 'out-of-the-box' thinking, by producing box plots for periods or eras. Out-of-the-box thinking becomes literally that - outside the box plot. The paper is concerned with identifying and classifying those outsiders and is not involved with the creative or innovative processes that brought them into being, though it touches on why some innovations were successful.

The paper deals with the outcome of the creative process and not with its internal elements: neither ideation nor selection. These do not necessarily remain historical mysteries, as insights into how individual automotive designers have worked are available, not just within the systems that manage the design process within the automotive companies. Texts such as Automobile design: twelve great designers and their work (Barker \& Harding, 1992) and Colin Chapman: Inside the innovator (Ludvigsen, 2010) outline something of the creativity utilized by individual automotive designers. Arguably aimed at the amateur automotive designer, How to design cars like a pro (Lewin \& Boroff, 2010), ignores the minutiae of creative processes, but includes a designer's diary, provides pictures of conceptual ideas and gives an outline of automotive design skills.

Investigating the historical outcome rather than the process itself, by observation, means that methods such as protocol analysis (Cross et al., 1996) are not available. It is only generally possible to gather information on Design processes and methods that are used by car designers in a second-hand manner and inferred rather than observed, because the observation was not carried out at the time.

\subsection{Being innovative doesn't sell automobiles}

People do not naturally love new ideas, particularly when they are asked to part with money to purchase novelty. They purchase a product to fulfill a need or desire. Products have to work reliably and effectively. Novelty doesn't necessarily do that: novel aspects need to be tested carefully to ensure they work and fulfill expectations. Automobiles have been around since the latter part of the $19^{\text {th }}$ Century. Since Henry Ford's Model T became successful (around 1910), most people wished to buy personal transport rather than, specifically, an automobile. If best selling automobiles are investigated, these are seldom at the forefront of change. However, change in automobile design does take place - otherwise we would be driving Ford Model Ts a hundred years after they were first introduced. 


\subsection{Definition of the automobile}

An automobile is generally taken to mean a privately-owned self-propelled road vehicle, usually with four wheels and an internal-combustion engine. For this study the definition includes those powered by steam or electricity and those with different numbers of wheels (usually three). Specially-designed taxis and small commercial vehicles are excluded.

\section{How to investigate innovation in automobile design}

There have been many approaches to the study of car history. These range from picture books aimed at a general readership (Roberts, 1985; Furman, 2003) to in-depth technical studies. They include anthologies of historical events (Cimarosti, 1997), general descriptive narratives (Boyne, 1988), catalogues of car manufacturers (BurgessWise, 1987; Culshaw \& Horrobin, 1997), histories of specific manufacturers (Filby, 1976; Sabates, 1986; Buckley, 1998; Feldenkirchen, 2003) and significant industrial studies including manufacturing trends and the analysis of sales figures (Abernathy, 1978; Womack et al., 2007). Whilst many concentrate on the main actor of the piece, the automobile, and some consider innovation and use their studies of the industry to act as examples of their innovation theories, few seem to analyze the actor in detail.

A larger study of car history was carried out by the author that aimed at understanding the development of car design by measuring and analyzing examples of automobiles. It used quantitative statistical methods to provide an overview of the changes that have taken place and qualitative methods to explain the findings. In general, historians have tended to favor qualitative, descriptive processes and develop narrative reasoning and analysis, tending to ignore the quantitative route. The statistical processes carried out in this longer study of the automobile have the ability to produce an eras map (Kumar, 2013), using numerical information rather than qualitative.

The statistical method used to investigate automobile history was to analyze examples of automobiles from 1878 onwards (Dowlen \& Shackleton, 2003). Initially some 453 examples of automobiles were chosen covering the whole of the date range, the basis for choice being opportunistic rather than rational. This included examples that were in the database solely because they were of interest, were seen on the road or in a museum.

These initial examples have been joined by a set of 143 UK best-selling examples: the data available for these does not cover the whole of the date range, and adding further examples to the database would be beneficial. The sampling process has not resulted in representative examples, particularly for early years, and it is extremely difficult to determine exactly what might be meant by a representative sample in this instance, and how one might be arrived at. There are several difficulties including the indeterminate nature of the population - does it consist of every automobile built, or does it consist of every type built, for instance? This lack of the sample being representative would be more important if the purpose of this paper was to understand 
general developments, but this is not the case. It is clear that significant characteristics and historical direction can be obtained from the sample that has been taken. From carrying out repeated analyses with slightly different data sets there have been no significant alterations in the results, although data for periods where there are few samples is more suspect than data for other periods, and this is particularly important if significant changes are seen during that time.

For each example nineteen categorical factors were analyzed for layout and twenty seven for form using the Categorical Principal Components analysis developed in the SPSS program. This reduces the data to a smaller number of components, each of which can be treated as a real number.

The term layout is a convenient shorthand term for factors that dictate major design parameters of the vehicle as a whole, and these tend to be categorical. They relate to the position and arrangement of the engine and transmissions, suspension type, driver positioning, direction control, body construction and the type of wheels and tires. Figure 1 shows a 1901 de Dion vis-à-vis with the layout variables identified for that vehicle, lettered for convenience.

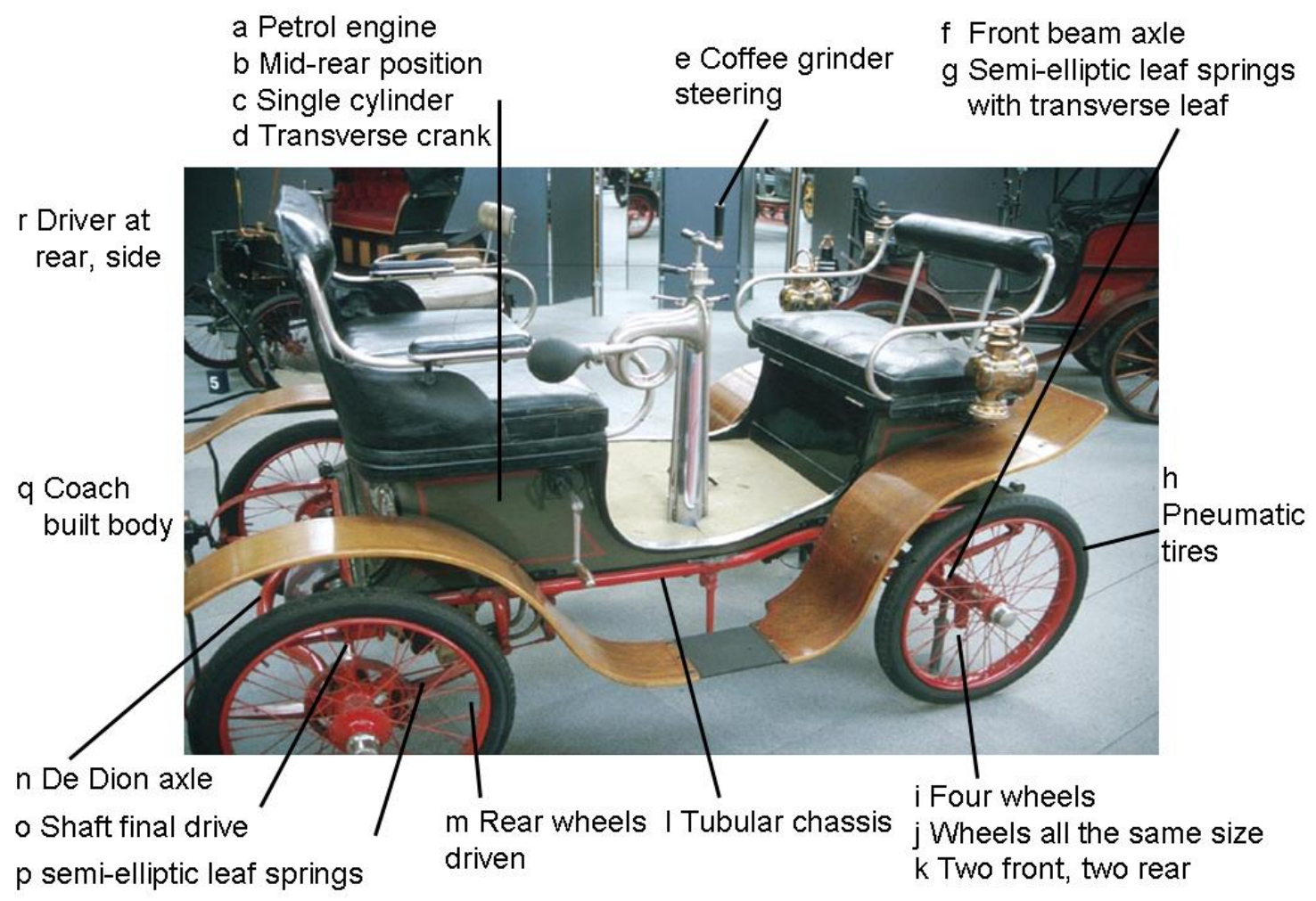

Figure 1: 1901 De Dion Bouton vis-à-vis with layout variables identified.

The de Dion does not have a conventional steering control, and the driver sits behind the front seat passengers. Being a de Dion, it displays the eponymous rear suspension developed for this particular model, allowing the engine and transmission to be mounted on the rear of the chassis whilst the axle is suspended. Only eighteen of the 
nineteen layout parameters are coded for this: the remaining parameter is engine cylinder arrangement, which is irrelevant with a single cylinder engine.

Form variables are those that are related to the form or shape of the car. Some form variables are categorical, such as the kind of lighting and fender shapes, but others were obtained by measurement and categorized for analysis. For most automobiles, direct side views were obtained, but for some it was necessary to develop approximations based on sizes of human figures, for example. The descriptors were initially descriptive, and changed to numerical for the analysis. Figure 2 shows the categorized form variables.

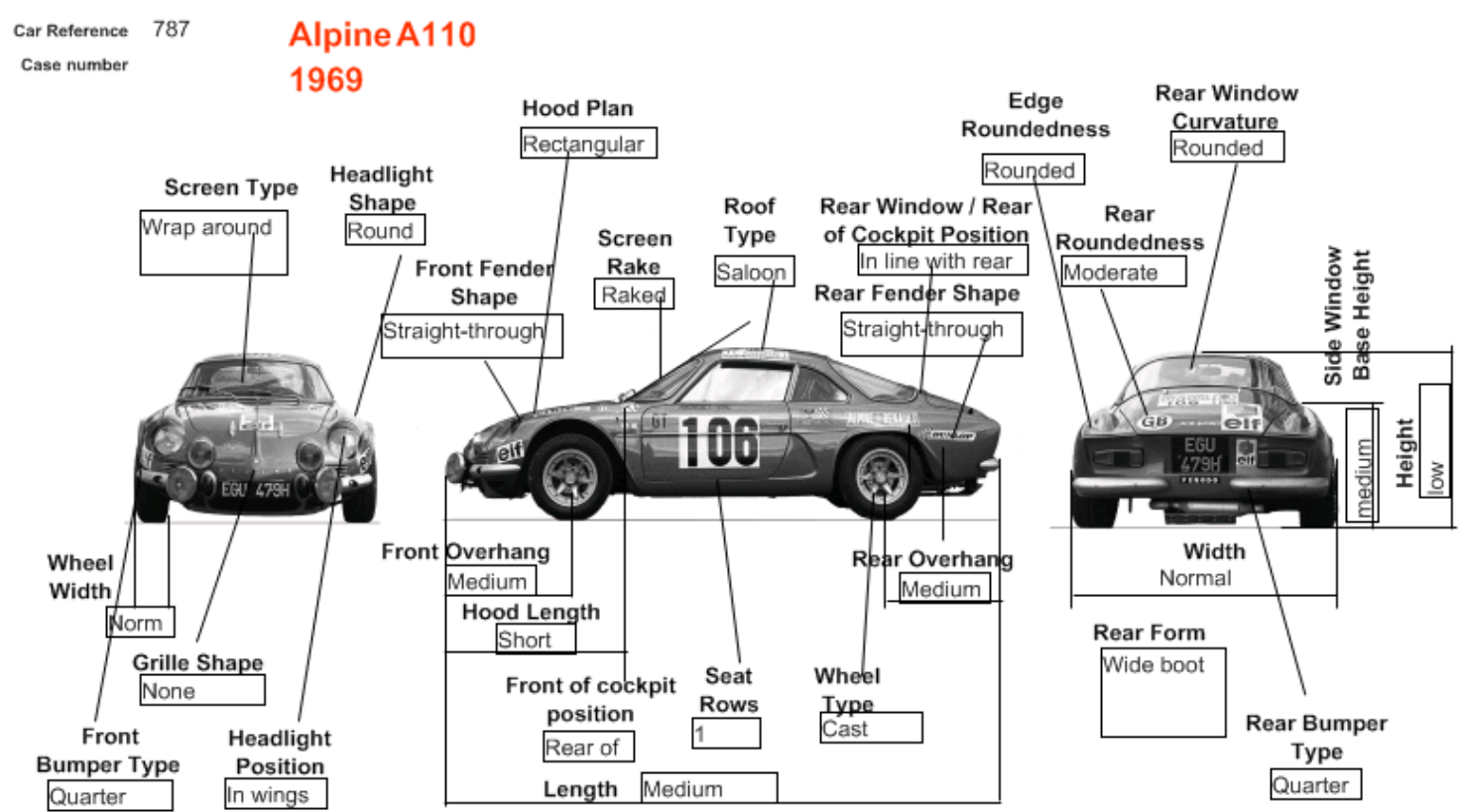

Figure 2: The variables used for the form analysis (Alpine A110 pictures (C) Nigel Burgess: used with permission)

When the Principal Component Analysis was carried out, this produced several components for each analysis. The first two components for each included about $80 \%$ of the variation and are therefore the most useful. These components can each be treated as real number variables and plotted against year of manufacture to allow a best fit line to be plotted (Figure 3). The numerical scales for these components refer to combinations of categories and the numbers do not measure anything that can be clearly identified, although investigation of the parameters can determine an overall description. Variables have not been graded for importance.

For a large proportion (about one quarter) the first and second layout dimensions lay within a very small range, and these examples were largely manufactured between 1905 and 1934. This can be seen in the top two graphs in Figure 3 where there are relatively horizontal lines between these two dates. This indicated the likelihood of a design paradigm, similar to the dominant design concept described by Utterback ( 1996) After that date the paradigm shifts and a new paradigm is established, but not for quite 
some time. Between the two dates (1935 to 1979) multiple paradigms are in operation, with no one being dominant.
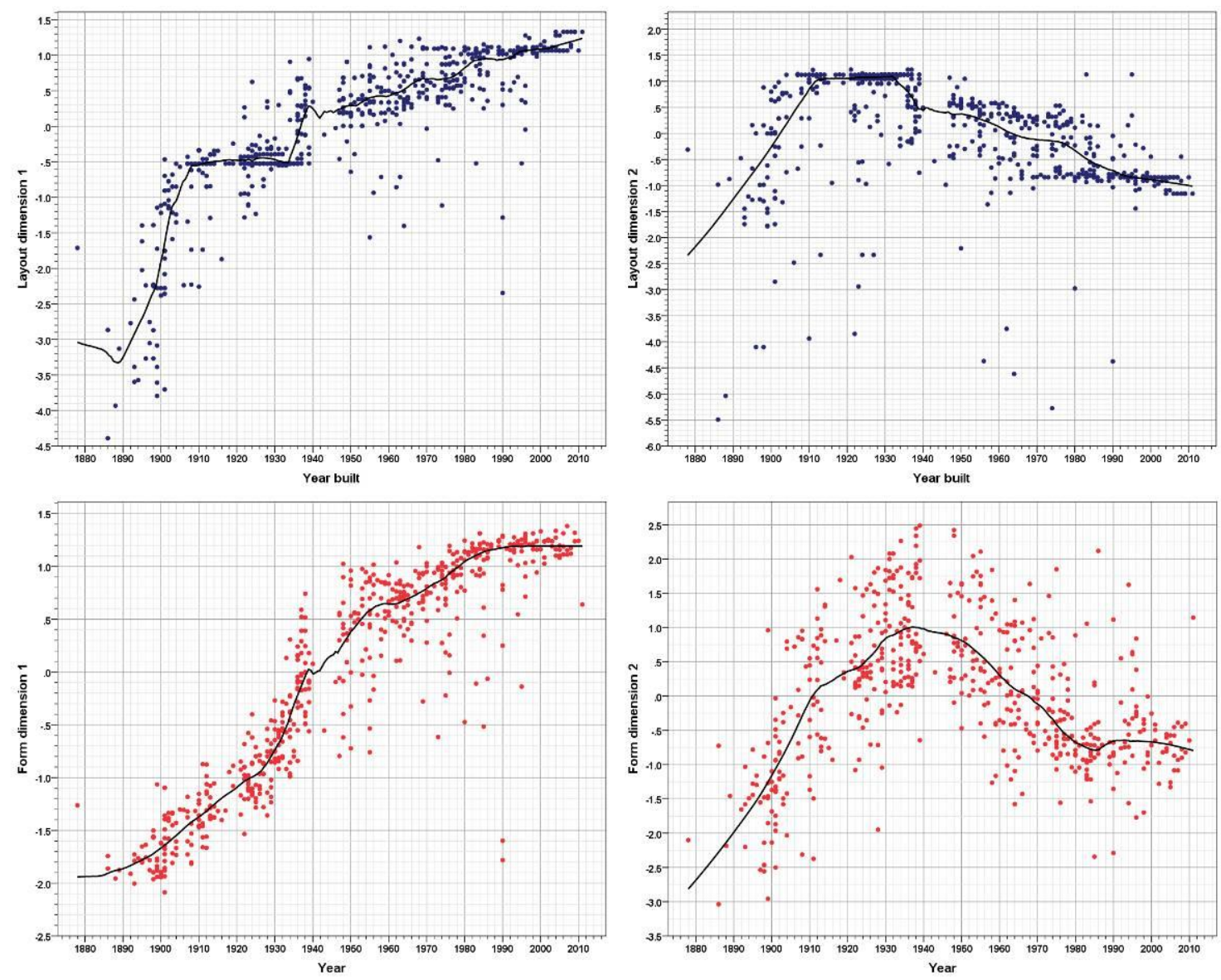

Figure 3: Categorical Principal Component plots for first (left) and second (right) components for layout (upper) and form (lower) analyses: components plotted against date.

The investigation in this paper is the converse of this. Rather than being a coherent statistical investigation that seeks to identify representative automobiles and to investigate the direction of change, this investigation deliberately looks at statistical outliers and categorizes them. The initial investigation, as stated above, selected automobiles opportunistically. This resulted in a mixed bag with little coherent reason for selection, on the basis that any automobile provided useful information. The initial sample included many weird and wonderful examples, some of which were outside the scope of the automobile definition such as a non-manufactured design and a disembodied chassis. In the process of attempting to obtain the representative analysis that is relevant to the greater automobile design history project, these eccentricities find their way to the edges of the statistics and are disregarded. This paper, conversely, takes the outliers of the investigation and seeks to investigate them in more detail. 


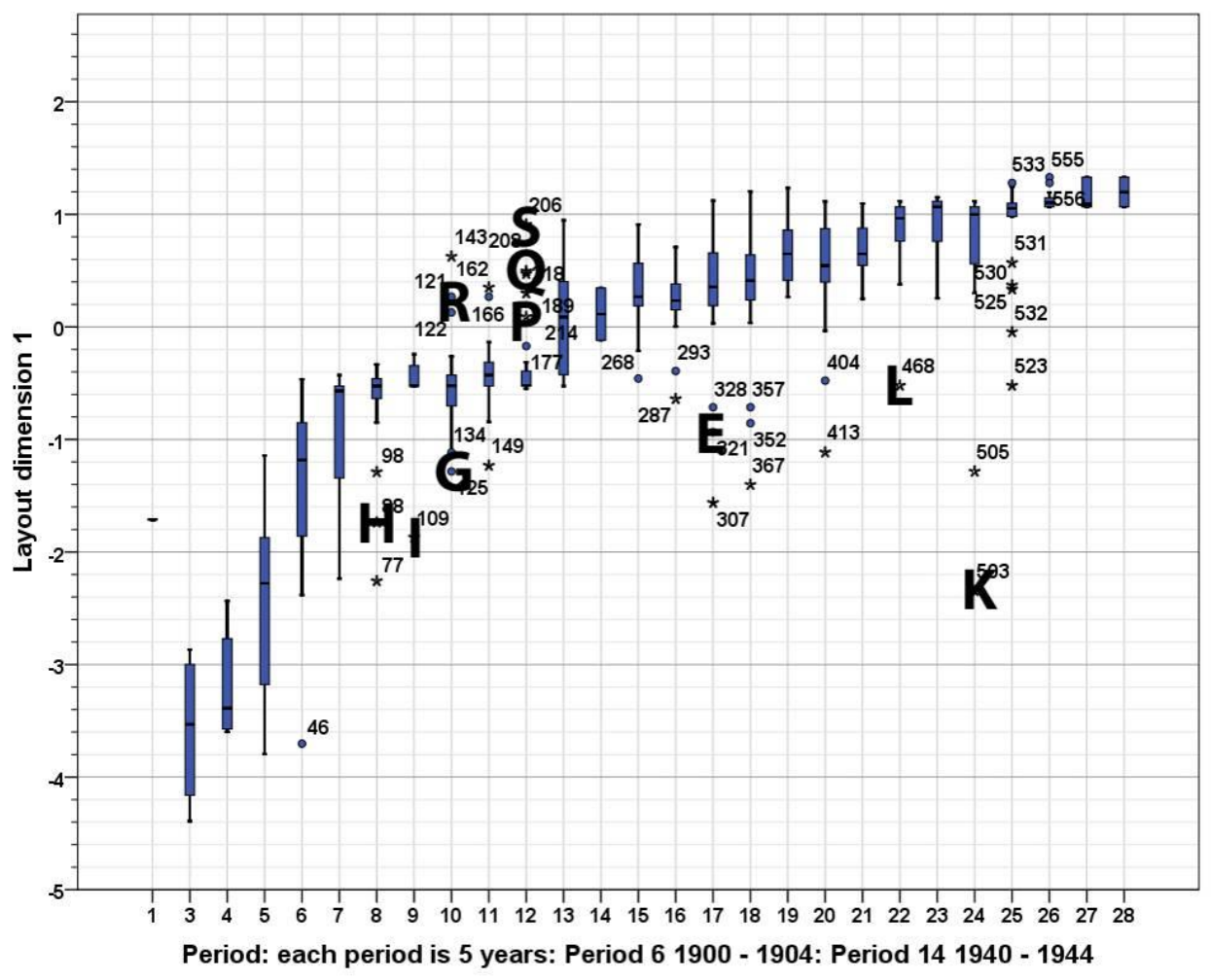

Figure 4: Categorical Principal Component box plots for first layout component plotted against period, (five years). Letters refer to Figures 8 to 12.

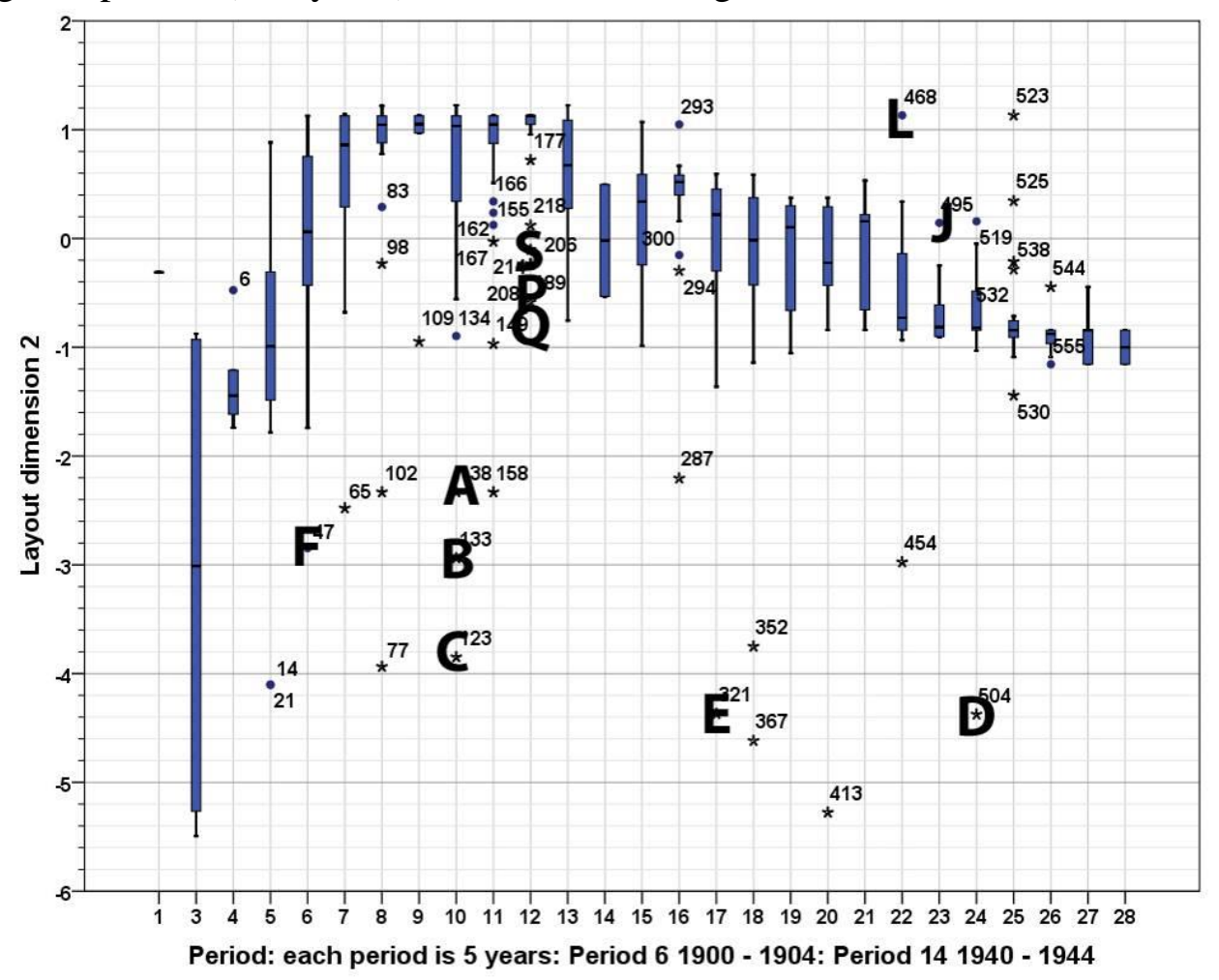

Figure 5: Categorical Principal Component box plots for second layout component plotted against period, (five years). Letters refer to Figures 8 to 12. 


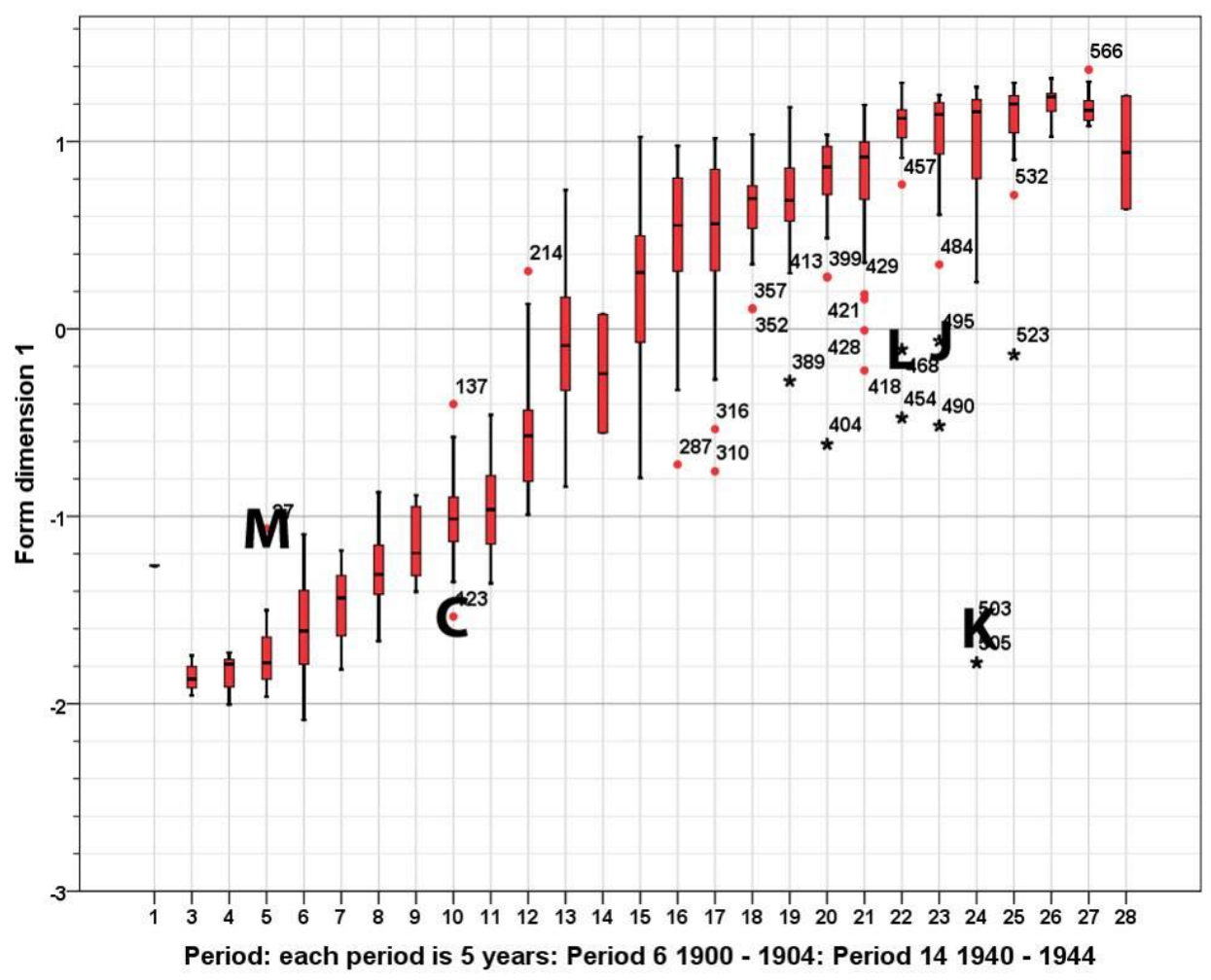

Figure 6: Categorical Principal Component box plots for first form component plotted against period, (five years). Letters refer to Figures 8 to 12.

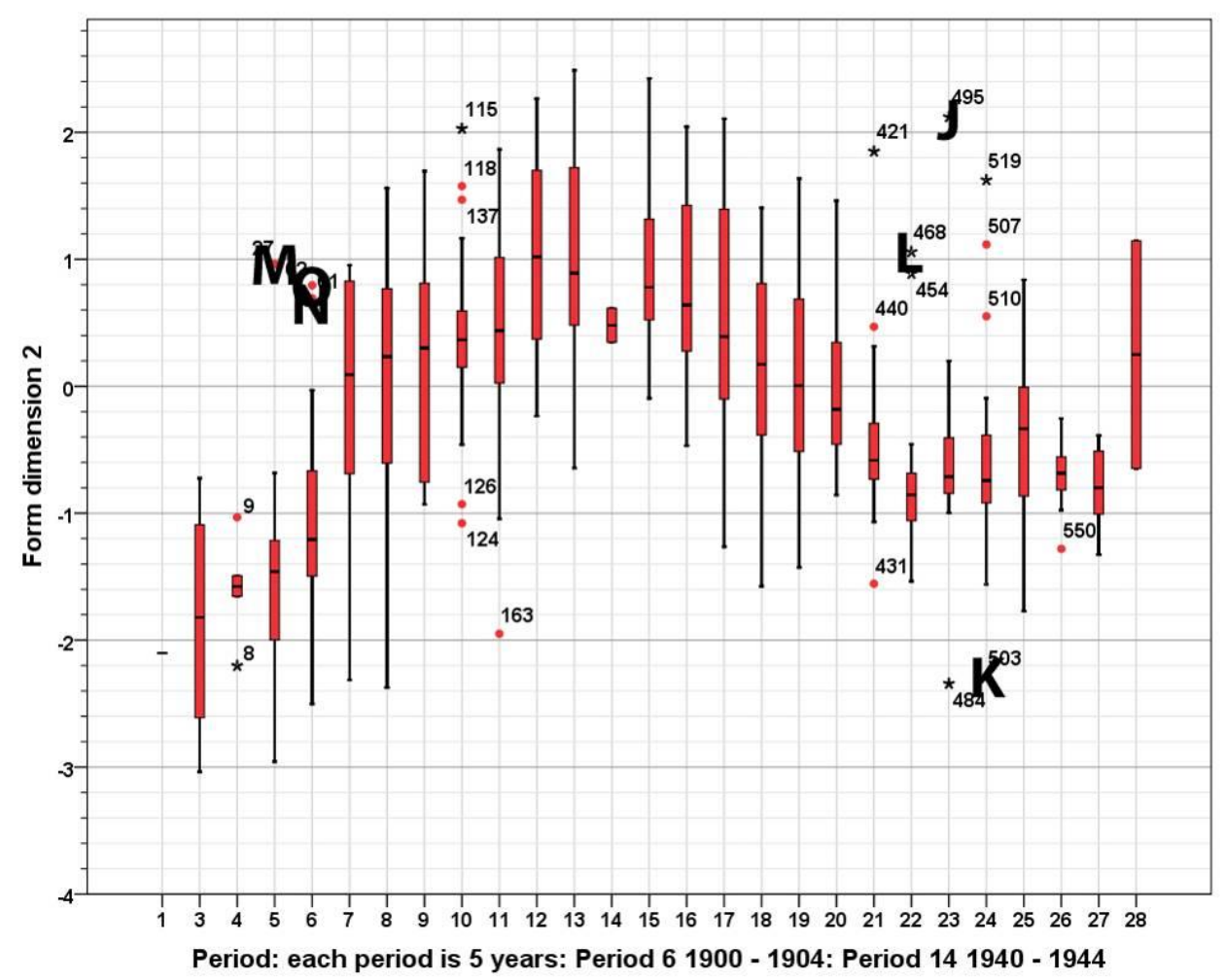

Figure 7: Categorical Principal Component box plots for second form component plotted against period, (five years). Letters refer to Figures 8 to 12. 
Figure 3 shows plots from the main analyses. Numerical values of variables do not mean much: the form of the graphs is more important and indicates changes and rates of change of the parameters. Each automobile is represented by a point on the graphs. There are 575 automobiles in this later analysis. Box plots (Figures 4 - 7) investigate the outer edges of the four graphs. To generate the box plots it was necessary to divide the time axis into periods, and an arbitrary five-year period was used for each of these, with each period starting with a year divisible by 5 . These plots identify the outliers and extreme values. The measure of central tendency used in creating the box plots is not the point on the best-fit lines in Figure 3, but the median.

There are some periods where the size of the sample is too small to make significant sense in the analysis. These are the first few periods, where there are very few examples of automobiles and where each one becomes an individual. In the first period there was only one example in the database, none in period two, from 1880 to 1884 and only three in the third, from 1885 to 1889 . Very few private automobiles were manufactured during the Second World War period, from 1940 to 1944 (Period 14), and there are similarly few examples in the database. The plots in Figures $4-7$ give the period number for this period: it does not seem possible to produce the plots with the period numbers replaced by dates.

Outliers were categorized initially using an affinity diagram approach (Cohen, 1995; IDEO, 2004). This produced several categories, with some automobiles in more than one category or linking two categories and many vehicles linking categories. A clustering analysis was also carried out using $\mathrm{K}$ values in SPSS, but the process of inspection was more useful, using the movement of the variables in the graphs in Figure 3 as the main criterion in determining suitable categories. Box plots are date-dependent and what is an outlier at one date may not be an outlier for another.

\section{Automobile outliers}

The affinity diagram approach indicated three main categories of outliers and automobiles with extreme values. The difference between categories lies in how they relate to the best fit of the variables. These three categories can be described as a) those outside the best fit for all dates after the first paradigm was formed: b) those that would not have been outliers if they had been earlier and c) those that would not have been outliers if they had been later.

\subsection{Automobiles which are always outliers}

The first of the categories tends to be at odds with the 'automobile' definition. This splits further into groups. Firstly, there are those having the 'wrong' number of wheels or wheels in the 'wrong' places. Three-wheelers are below the best fit line of the upper right diagram of Figure 3. Examples of five three-wheeled automobiles are shown in Figure 8. The sixth automobile in Figure 8 is the 1901 Sunbeam-Mabley (F) - with four wheels in diamond formation. The three-wheeled examples include a 1924 Morgan (A) and a Messerschmitt (E) with the single wheel at the rear, a 1922 Phänomobil (C) 
with the single wheel at the front, and two with one wheel on one side and two on the other: a 1922 Scott Sociable (B) and the 1990 Monash University solar-powered automobile (D).

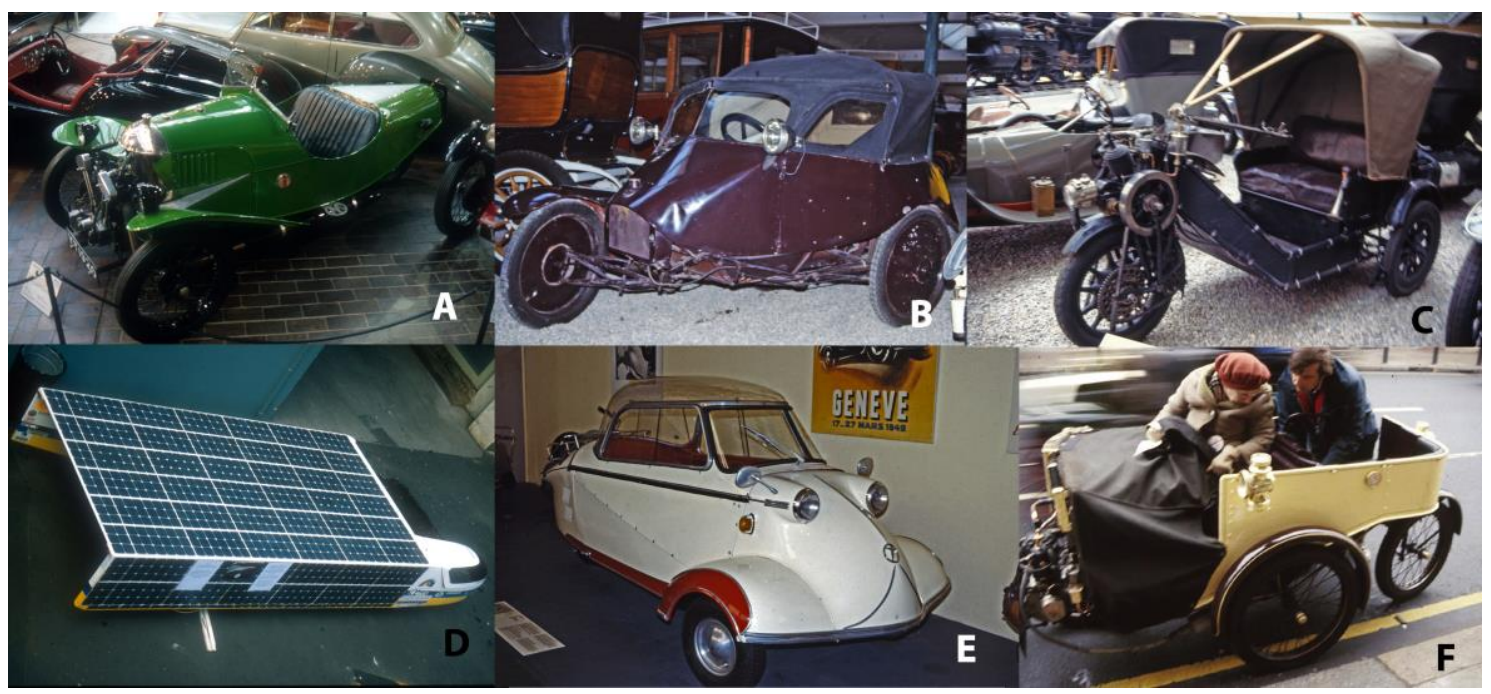

Figure 8: Odd arrangements of wheels. 1924 Morgan (A), 1922 Scott Sociable (B), 1922 Phänomobil (C): lower row, L to R: 1990 Monash University solar-powered automobile (D), 1956 Messerschmitt (E), 1901 Sunbeam-Mabley (F)

Automobiles in a second group in this category do not have internal combustion engines, such as the Monash University solar-powered automobile (D). Some other examples are shown in Figure 9. One might argue whether these are throwbacks to the date before the internal-combustion engined paradigm was formed, or whether they are independent and deliberate attempts to be different, for whatever reason: ie whether they belong in this first category or in the second. These are slightly below the mean line in the upper left diagram in Figure 3. In early days electric or steam-powered automobiles are not extreme and are not outliers. Only a few manufacturers failed to change to internal-combustion engines, and steam and electric automobiles become oddities. These manufacturers were not moving with the rest of the industry, rather than deliberately pushing boundaries.

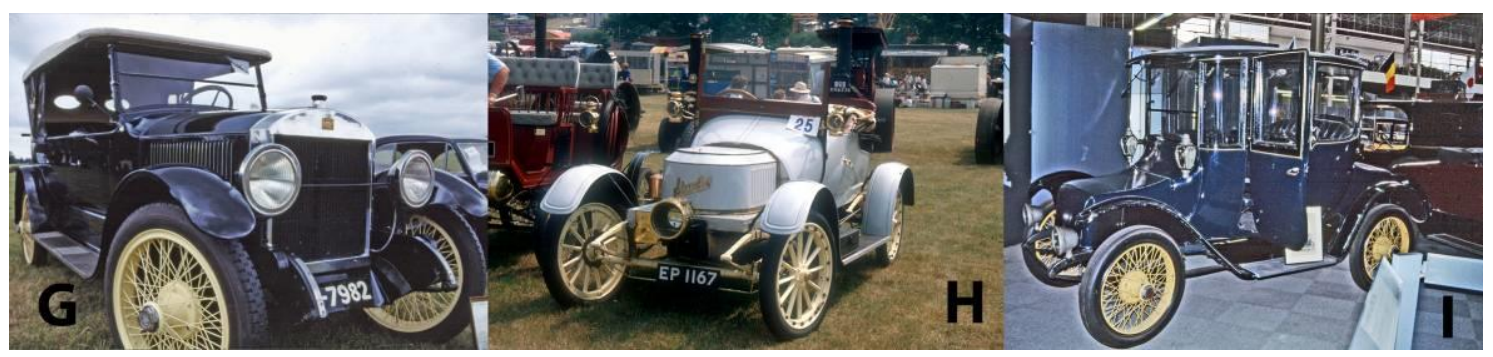

Figure 9: Steam and electricity: 1922 Stanley (G), 1911 Stanley $(H)$ and 1916 Detroit Electric (I) 
Automobiles in both of these categories may have other features that are out of line with the perceived paradigm as well. The Phänomobil (C), Sunbeam-Mabley (F) and Detroit Electric (I) are tiller-steered: the Messerschmitt (E) has handlebars. The Detroit Electric (I) and Sunbeam-Mabley (F) seat the driver at the rear. The Messerschmitt (E) and Sunbeam-Mabley (F) have tandem seating with driver and passenger in the centre.

\subsection{Replicas}

The second category is automobiles that would not have been outliers if they were earlier. This may include automobiles powered by steam or electricity where this is a throwback to pre-paradigm dates. Some vehicles are deliberately throwbacks and are historical replicas. Their design process constitutes deliberate flouting of the status quo of automobile design: disagreeing with the state of the art when they were built. This category splits into those which are precise copies, and those which are intended to copy the flavor of an era. Figure 10 shows three such automobiles.

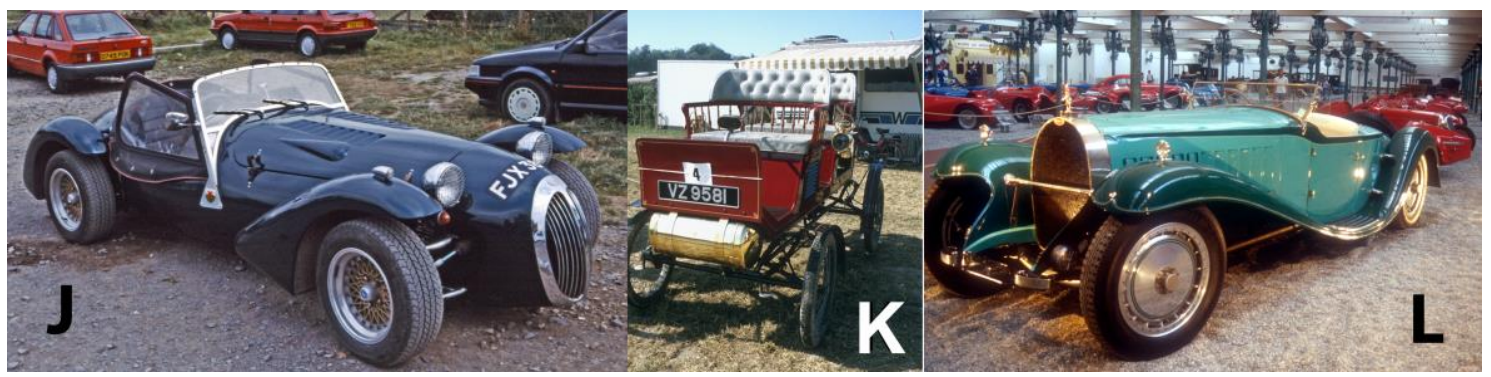

Figure 10: 1986 Kougar (J), 1990 Locomobile replica (K), 1989 Bugatti Royale Replica (L)

Each of these three replicas takes a different approach and the dates they are copying mean that they are in different positions on the charts in Figure 3. The Kougar (J) does not copy anything, but picks up the character of a 1950s open-wheeled sports automobile. There is no attempt to make the wheels fit the 1950s date - these are 1980s. On the right is a straight copy of the 1932 Bugatti Royale (L), using original parts to recreate a replica of a particular vehicle. In the middle, the Locomobile replica (K) seeks to look and work like the 1900 Locomobile steam automobile - it has a steam engine - but has recent parts (such as front brakes) to make it legal. In all three cases, wanting something different and historical has been the spur to re-creation. In both layout and form, these date not from when they were made, but from the date they are copying.

\subsection{Innovators}

More constructive is a study of the third category of automobiles: those that are the opposite of the replicas. This category is of those that would not have been outliers if they had been later. These may be seen as being innovators. 
Abernathy defines innovation as 'a major improvement or series of improvements in what [he refers] to as a "design approach"'(Abernathy, 1978). Kumar (2013) defines it as 'a viable offering that is new to a specific context and time, creating user and provider value'. Abernathy's definition only refers to the novelty aspect and not the viability or value: Kumar's definition includes the two aspects of novelty and value. This tends to be more in line with other definitions.

In the case of this particular study, innovation is evidenced in that the examples are not simply new and different, but that they are new different in ways that become commercially successful and also, crucially, in ways that determine the future direction of the course of the automobile industry and therefore offer leadership. This latter definition of innovation (i.e. that of being imitated) adds to both definitions above and is not generally included within other traditional definitions of innovation. Examples of this type of innovation can be seen in different periods.

\subsubsection{A nineteenth century innovator}

The first example in this category is one that does not technically figure as an outlier. This is the single earliest example which dates from 1878, La Mancelle by Amedée Bollée, père, illustrated in Figure 11. This is on the far left of each of the plots in Figures 3 - 7. In 1878 this vehicle had wheel steering and independent front suspension, with the engine placed well to the front. It acts not as a precursor to the paradigm established around 1904, but beyond to the 1930s. Barker and Harding (1992) ask whether Amedée Bollée was before his time, concluding that the public response to his work did not suggest so. However, his inclusion within Barker and Harding's book confirms that they regarded him as just that. They state that La Mancelle's front suspension system was 'so progressive that it has remained a feature of automobile design almost to the present day'.

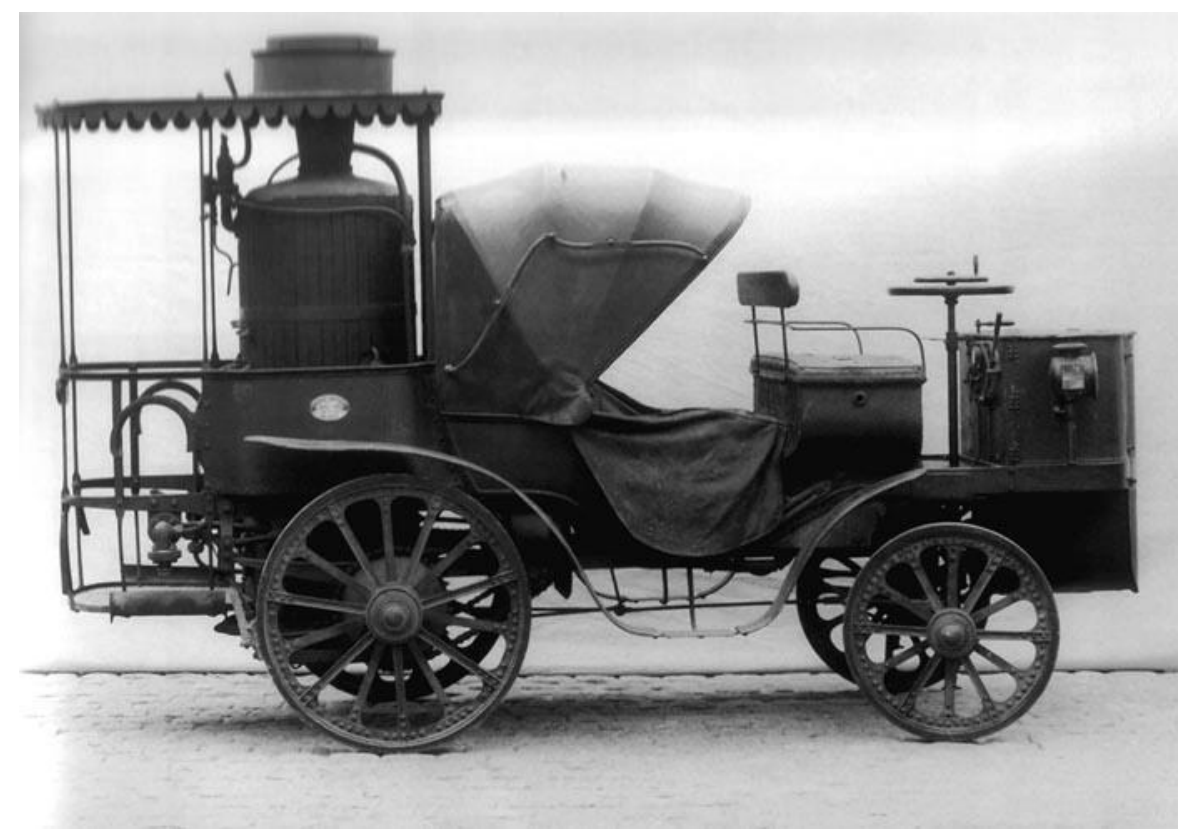


Figure 11: La Mancelle by Amedée Bollée, père: 1878 (Kupélian, 1997). Used with permission.

\subsubsection{Innovators from the early years of the twentieth century}

In the early years of the twentieth century three automobiles stand out as being outliers above the line in the lower right diagram of Figure 3. They are seen in Figure 12. One is Jenatzy's La Jamais Contente. This was an electrically powered record vehicle. Its layout is not trend setting, but its form is more integrated (component 1) and longer and lower (component 2) than other automobiles of the time. Although trendsetting for form it is outside the mainstream direction. The other two show direction better, and are a 1904 Mercedes and the 1904 Peerless Green Dragon. These were precursors of a change in (form) design, where automobiles became longer and lower, with long bonnets at the front with a relatively small passenger area behind. This change was made possible by the (layout) development of the pressed-steel channel-section chassis.

Mercedes is generally regarded as a pioneer at this sort of date. Mercedes-Benz themselves, not unreasonably, state that 'Maybach designs the first modern car' in their museum history (Lengert et al., 2006), but that reference may be biased. ScottMoncrieff confirms that 'There is little doubt that the appearance of the 35-hp Mercedes at Nice in the spring of 1901 influenced the design of motor-cars of the future' (ScottMoncrieff, 1963). The 1904 Mercedes is a direct descendant of this. Scott-Moncrieff comments that Peerless was the first American manufacturer with a channel-section chassis in 1903, and describes several of the company's other advanced and innovative features.

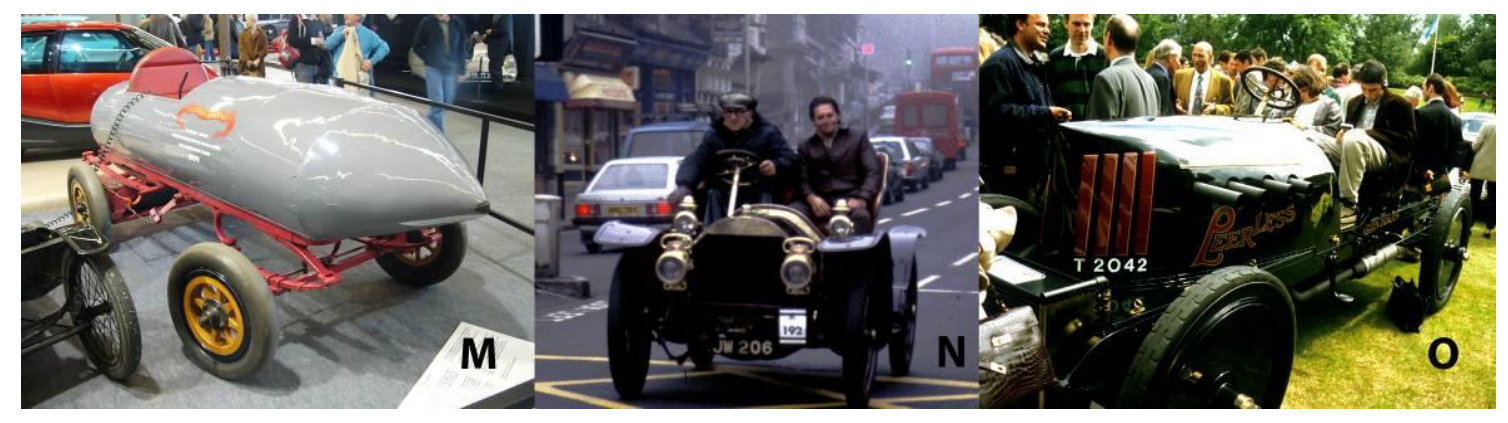

Figure 12: 1899 La Jamais Contente (M), 1904 Mercedes (N), 1904 Peerless Green

Dragon $(\mathrm{O})$

\subsubsection{Innovators from the early 1930s}

The second major period of innovation is in the 1930s. These automobiles demonstrate developments in layout, and are outliers above the line in the upper left diagram of Figure 3, and just below it in the upper right one. During this period most automobiles had longitudinal engines in the front, rear wheel drive, rigid front and rear 
axles and separate pressed-steel chassis. But some designers were pushing boundaries. They may have included independent suspensions; rear engines, transverse engines, or monocoque chassis.

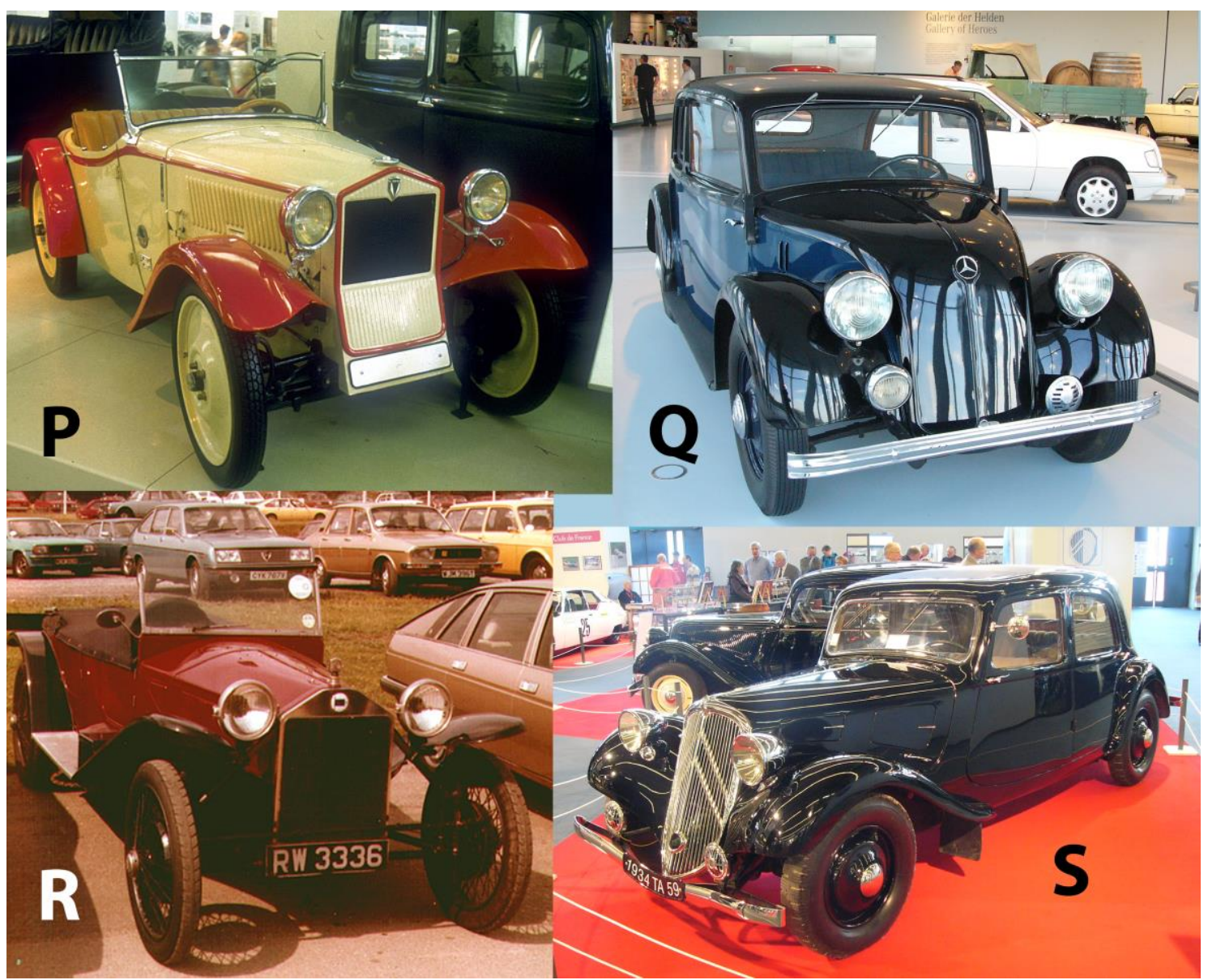

Figure 13: 1931 DKW F1 (P), 1934 Mercedes-Benz 130H (Q), 1925 Lancia Lambda (R), 1934 Citroën 7A (S)

Figure 13 shows four different directions that automobiles might have developed.

$\mathrm{P}$ is the $1931 \mathrm{DKW} \mathrm{F} 1$. Its front wheel drive, transverse engine, independent front suspension and unusual structure push it above the best fit line, but its twocylinder two-stroke engine pushes it down a little. It was a German development of the small automobile, built for the masses in an economical manner. Whether the designer considered it as progressive is unclear. The Wikipedia website (not always the most reliable) simply states that the company was 'progressive' (Wikipedia). Sedgwick (Georgano et al., 2001) suggests DKW led the use of front-wheel drive in the 1930s and that it was no longer considered a heresy. This suggests that although its design was outside normally-accepted codes of practice, this was stretching by 1931. Although not the first recorded use of a transverse engine and front-wheel drive (this seems to have been an 1895 Graf, one of which is in the Technical Museum in Vienna (Hantschk \& Schaukel, 1988)), it seems to have been the first time this was used in a mass-produced 
automobile. Although DKW and Trabant continued with this layout, the next serious example of it was the 1959 BMC Mini.

The second example, Q, is a rear-engined Mercedes-Benz. In the early 1930s, several manufacturers suggested that the 'proper' place for an engine was at the rear and that the driveline between front and rear was illogical. Most of this development came from middle Europe; Germany and Czechoslovakia, with examples from Benz, Rumpler, Hänomag, Mercedes-Benz, Auto Union, Tatra and Volkswagen. Of these, the Benz and Auto Union were racing automobiles and the Rumpler never made production. Most also adopted independent suspension, which was a more important development. The layout had some following from the mid-1930s, dying out largely as late as the 1970s, although there are still examples manufactured currently (2013). Though it probably had its roots in the German rationality of the Bauhaus, the logicality to placing the engine at the rear did not confer significant advantages over a frontengined arrangement - but in the 1930s it was considered progressive, and managed to flout the accepted codes of practice.

Mercedes-Benz state that the $130 \mathrm{H}$ was the world's first car in large-scale production with this layout (Lengert et al., 2006). Ason Holm (Georgano et al., 2001) makes a short reference to the car, mainly describing its shortcomings derived from the rearward weight bias. He treats the vehicle as a prelude to the more definitive Volkswagen. He doesn't see the rear engine arrangement as a significant innovation, although he describes several vehicles of that time with the configuration.

The 1934 Citroën (S) combined front-wheel drive, independent front suspension and unitary body-chassis construction. These last two attributes were copied to a greater extent than the front-wheel drive. Sedgwick refers to the car as 'an astonishing leap forward by a firm to whom progress had hitherto been synonymous with bargainbasement prices and advanced manufacturing techniques' (Sedgwick, 1967).

The lower left example dates from earlier, and is a 1925 (designed earlier) Lancia Lambda. This used independent front suspension and unitary-construction. It is now regarded as one of the most sought-after automobiles of the 1920s, described in Classic and Sportscar magazine as the first production monocoque automobile; innovative and with excellent handling (McKay, 2012).

\subsubsection{Innovators in the 1990s}

Another group of innovators on the edge of the box plots is a group from the 1990s and early years of the current century. These are diesel-engined automobiles, in advance of general market acceptance. The first diesel engined production automobiles were probably built by Mercedes-Benz as long ago as 1936 (Lengert et al., 2006); it has taken from then to the 1990s for diesel automobiles to achieve market acceptance. These signal the start of a change in market acceptance of the diesel, once perceived as smelly and low-powered, into the mainstream of acceptability. 


\section{The anatomy of an innovation}

None of these developments in automobile design have the character of the disruptive innovations described by Christensen (1997) and illustrated by the development of the Turbojet (Constant, 1980) as they do not require significantly different manufacturing technologies to be implemented.

Abernathy (1978) outlines twenty automotive innovations, picking out both independent suspension and unit body construction as being the most significant innovations from the 1930s decade. He expounds the process for the selection of the twenty innovations that he selects in some detail. His conclusions are similar and confirmatory. He also includes innovations in engine design and manufacture which were not covered in this current study.

What turns something that is merely outside accepted wisdom into an innovation? And why did technologies such as monocoque body-chassis construction, independent front suspension and front-wheel drive became successful innovations whilst the middle European approach with a rear engine did not? And why did it, in some cases, take so long from the earliest use of a particular arrangement to its being accepted as an innovation?

The difference in eventual acceptability seems to be that developments become innovations after clear advantages are demonstrated that are then translated into an improved product for the customer. For instance, in the case of the use of independent front suspension compared to non-independent suspension the main advantage is to do with the automobile's roll behavior, which allows the independently-suspended automobile to have a softer suspension. This improvement in ride quality sold the arrangement to the General Motors management in the early 1930s, and was deemed to be a noticeable advantage for customers. Independent front suspension also allows the engine to be moved forward between the front wheels, giving more usable space. This movement changes the direction of the second form dimension in the lower right diagram in Figure 3. The improvements arising from monocoque structures are mainly to do with the manufacturing advantages as a logical approach that reduces component numbers. Customer perception of the improvement comes from improved use of interior space, more attractive integrated whole, and more stiffness for the same weight.

\section{Conclusions}

The title for the paper originally came from a discussion where someone stated that interesting things happen at the edges where disciplines meet and collide. The original context was that of academic disciplines and how cross-disciplinary thinking can lead to novel developments. But this paper looks at the interesting things at the edges of automobile history. It is also a sideways look at statistical analyses: that of analyzing the deviant rather than the norm, devising a process of using the outliers to do so and gathering and classifying the data to identify categories and groupings. This may provide an insight into how developments and ideas turn into either dead ends or innovations. 
The analysis process indicates that thinking outside the box is not sufficient to generate innovation. The historical examples of out-of-the-box thinking include those that are always considered to be outside of the box, usually because they fall outside market acceptance of the product as a saleable, marketable automobile. They may be considered products that entice a marginal market into mobility, such as three-wheeled vehicles, or may have been designed for a limited market, such as the steam and electric automobiles in the 1920s period, or for no market sales at all, such as the solar-powered cars. Alternatively, they may have been automobiles that would have been inside the box in the past, and which were deliberately courting heritage by emulating past, outdated designs for historical reasons for the small market that demands historic reference in the product, such as a well-heeled steam enthusiast might enjoy as a hobby. Only the third category of out-of-the-box thinking relates to developing innovation, in that these examples display thinking that would at some later stage become part of the norm.

An investigation of the central tendency, in this case, is unlikely ever to produce a meaningful discussion of specific examples of innovations, as this lags behind those that lead the changes.

It also indicates that statistical or quasi-statistical techniques can lead to insights that require other processes to investigate them, and ties the analytical analysis process to conventional historical discussion of description and narrative. These can explain and make further sense, attempt to attribute causality and identify reasons behind the changes and developments that are identified.

The investigation of outliers offers a useful contribution to investigation of product history and is helpful in identifying strands and wrinkles that take place within any product history. It is offered as a positive contribution to a methodical study of product history.

\section{References}

Abernathy, W. J., 1978. The Productivity Dilemma: Roadblock to innovation in the automobile industry. Baltimore \& London: The John Hopkins University Press.

Barker, R., \& Harding, A. (Eds.). (1992). Automobile Design: Twelve great designers and their work. Warrendale, PA: Society of Automotive Engineers.

Boyne, W. J., 1988. Power Behind the Wheel: The Evolution of Car Design and Technology. London: Conran Octopus.

Buckley, M., 1998. Jaguar: fifty years of speed and style. Sparkford, Nr Yeovil, Somerset: Haynes Publishing.

Burgess-Wise, D., 1987. The Illustrated Encyclopedia of Automobiles. London: New Burlington.

Christensen, C., 1997. The innovator's dilemma: when new technologies cause great firms to fail Boston, Mass: Harvard Business School. 
Cimarosti, A., 1997. The Complete History of Grand Prix Motor Racing. London: Aurum.

Cohen, L., 1995. Quality Function Deployment: How to make QFD work for you. AddisonWesley Longman.

Constant, E. W., 1980. The Turbojet revolution. 1980. Baltimore, Maryland: John Hopkins University Press.

Cross, N., Christiaans, H., \& Dorst, K., 1996. Analysing Design Activity. Chichester: John Wiley.

Culshaw, D., \& Horrobin, P., 1997. The Complete Catalogue of British Cars 1895 - 1975. (2006 ed.). Dorchester: Veloce Publishing.

Dowlen, C. (2012). Creativity in car design - the behaviour at the edges Paper presented at the The 2nd International Conference on Design Creativity (ICDC2012), Glasgow, UK.

Dowlen, C., \& Shackleton, J. (2003). Design History of the Car: an Empirical Overview of the Development of Layout and Form. Paper presented at the ICED'03: Research for Practice: Innovation in Products, Processes and Organisations, The Royal Institute of Technology, Stockholm, Sweden.

Feldenkirchen, W., 2003. Vom Guten das Beste: vom Daimler und Benz zur Daimler-Chrysler AG: Band 1: Die ersten 100 jahre (1883 - 1983). Munchen: Herbig.

Filby, P., 1976. TVR. Success against the odds. London: Wilton House Gentry.

Furman, M., 2003. Motorcars of the Classic Era. Harry N Abrams Inc.

Georgano, N., Sedgwick, M., \& Ason Holm, B., 2001. Cars 1930 - 2000: The birth of the Modern Car. New York: Todtri.

Hantschk, C., \& Schaukel, G. (1988). Automobile im Technischen Museum Wien. Wien: Technischen Museum Wien.

IDEO. (2004). IDEO Method Cards.

Jones, J. C., 1981. Design Methods: seeds of human futures. Chichester: John Wiley \& Sons.

Kumar, V., 2013. 101 Design Methods: a structured approach for driving innovation in your organization. Hoboken, NJ: John Wiley \& Sons.

Kupélian, J., 1997. L'Europe automobile / Het Europa van de automobiel / Europe on Wheels. Brussels: Autoworld, Brussels.

Lengert, A., Dreher, A. M., \& Heidbrink, G., 2006. Mercedes-Benz Museum: Legend \& Collection. Stuttgart: Mercedes-Benz Museum.

Lewin, T., \& Boroff, R., 2010. How to design cars like a pro. Minneapolis: Motor Books.

Ludvigsen, K., 2010. Colin Chapman: Inside the Innovator. Teovil, Somerset: Haynes.

McKay, M., Bentley 3-Litre. Classic and Sportscar, April 2012 (issue), 324.

Roberts, P., 1985. The History of the Car. London: Deans International Publishing. 
Sabates, F., 1986. Les Prestigeuses Citroën. Paris: Ch. Massin.

Scott-Moncrieff, D., 1963. Veteran and Edwardian Motor Cars. London: Batsford.

Sedgwick, M., 1967. The "Traction Avant" Citroëns, 1934 - 1955. Leatherhead: Profile Publications.

Utterback, J. M., 1996. Mastering the Dynamics of Innovation. Boston, Mass: Harvard Business School Press.

Wikipedia. $D K W$ [online] Available from: http://en.wikipedia.org/wiki/DKW [Accessed 21 March 2012]

Womack, J. P., Jones, D. T., \& Roos, D., 2007. The machine that changed the world. London: Simon \& Schuster. 